\title{
Research on Ways to Improve the PPP-Related Value for Money Assessment under the Perspective of Jurisprudence
}

\author{
Ye Zhao \\ Economics Teaching and Study Department \\ The Party School of CPC Liaoning Province Committee \\ Shenyang, China
}

\begin{abstract}
Value for Money (VFM) is a method that is used to assess whether the PPP mode is adopted to replace traditional governmental purchase mode for infrastructure and public service projects, which is very necessary to regulate the VFM via documents. Currently there are still many problems existing for the system needing further improvement, seen from the jurisprudence, we should start with the relations of rights and interests between public capital and private fund, improvement of capital utilization rate, reduction of capital risk and so on.
\end{abstract}

Keywords-PPP mode; VFM assessment; perspective of jurisprudence

\section{INTRODUCTION}

PPP mode refers to a partnering cooperation established between government and private organizations in order for the construction of urban infrastructure projects or supply of some public goods or service on the basis of concession agreements, besides, contracts are signed to clarify rights and obligations between two sides so as to guarantee the cooperation and achieve a better results than that will be got through single party action for both parties. At present, the PPP mode has been widely advocated by central and local governments to resolve government debts. In order to make the PPP mode go well, in 2015, Instruction for Value for Money Assessment of Public-Private Partnership Project (Trial) was released by the Ministry of Finance. Value for Money (VFM) is a method that is used to assess whether PPP mode is adopted to replace traditional governmental purchase mode for infrastructure and public service projects, which is very necessary to regulate the VFM via documents. It provides premise and guarantee for the healthy development of PPP projects in the country. However there are still many problems existing for the system needing further improvement,

\section{DEFECTS OF CURRENT VFM ASSESSMENT IN CHINA}

\section{A. Scoring System of Qualitative Analysis Makes Projects} More Subjective

In practice, the PPP projects are just assessed through scoring by experts in accordance with Instruction for Value for Money Assessment of Public-Private Partnership Project (Trial). Generally, there are seven basic indices and 7 optional indices. Out of the optional indices, select 3 indices at least to form ten indices for assessment, and experts will mark with an scope of 0-100 points. There are totally seven experts who are involved in engineering, finance, project management, laws and so on. Under the system, the qualitative analysis means that the average value of each index's points multiply the weight of its own, if the sum of all points exceeds 60 , it shall be considered VFM at the qualitative analysis. However, each expert holds authoritative judgment at what they are familiar at but not at other fields. Therefore, the average score is meaningless, besides, the points of experts which may be the lowest or the highest will be removed, as such, the subjective judgment is further enlarged.

\section{B. Too Many Barriers to Push Quantitative Analysis}

There are many problems just seen from the benefits. During the assessment of each plan, we need to assess the benefits of each plan. Yet the PPP projects are mainly gathered at semi-public goods such as infrastructure. The semi- public goods have features of publicity such as benefiting the people and satisfaction by the people to the project, which are theoretically necessary for the plan. However, actually there are bigger barriers for the quantification, for the attitude and satisfaction of the people generally are unable to monetize.

\section{Tedious Procedures with High Costs}

For the VFM assessment, it needs to compare the current value of traditional government purchase plan and the current value of the plan in PPP mode; screen different PPP plans, calculate and compare the costs and benefits of each plan, the calculate the costs and benefits of each activity and 
assess and calculate any changes due to the activity. During the course, relevant data collection, process, statistics and calculation all need more man power and properties, which cause the sharp increase in cost.

\section{Imperfect Data System}

Seen internationally the VFM system achieved a lot after its application in Japan, for it depends on the perfect data source system and real data in the country, yet the data system is imperfect in China. In addition, we have a large territorial area, and the customs and habits vary with the regions, such regional difference makes it difficult to form a risk data system uniform and applicable for all regions. Besides, for some PPP project contracts will last for a long time even more than 50 years, with the time going, all kinds of uncertainties are increasing, which make it much more difficult.

\section{IMPROVEMENT ON VFM ASSESSMENT FROM THE PERSPECTIVE OF JURISPRUDENCE}

In order to judge whether the VFM assessment system is good or bad, it needs to introduce the predicted goal and value orientation to be achieved for the PPP mode as well as whether the ways and procedures to achieve the goals are operable or not. Seen internationally, the reason to introduce the PPP mode is mainly because, compared to traditional governmental investment and purchase mode, it has unique advantages such as lower costs, risk sharing, higher efficiency and win-win between governments, private capital and the society. However, in practice we need to carefully deal with the problems existing possibly as to reach the goal as expected, otherwise, it will be out of expectation. In addition, today we have been advocating and building a legal society, law based governments and a legal country, it is must for use to math the PPP VFM assessment system to the legal construction and law system in the country. Therefore, we will conduct rational analysis on the VFM assessment system at the perspective jurisprudence aiming at the following:

\section{A. The VFM Assessment Shall Weigh the Relations of Rights and Benefits between Governmental Public Capital and Private Capital}

The PPP mode is a cooperation between governmental public capital and private capital, which is a cooperation between equal subjects at private laws, namely during the cooperation, the rights and obligations between the government standing for public capital and private bodies standing for private capital. However, seen actually, the cooperation between government and privates is not completely the same as the relations between equal subjects at private laws. Because, first, seen from the economics of the law, the government is an agent for public capital, and the government investment is vulnerable to diseconomy, which will lower the capital utilization efficiency. Second, after all, the government owns the public power, which causes the physical inequality between governmental public capital and private capital, as a result, the governmental public capital will predominate ye the legal rights and benefits of private capital cannot be guaranteed, or relying on the public power, the government may seek rent, which cause the security of governmental public capital is at a risk, damaging the public interests possibly. Therefore, we should value how to weigh the rational rights and benefits of governmental public capital and private capital under the VFM assessment system. If it cannot be well dealt, the advantages of the PPP mode will be unable to exert, it will be harder to develop healthily. Therefore, the VFM assessment is a criteria and baton for the PPP's healthy and sustainable development, we need to keep the balance between the governmental public capital and private capital, keep it going as it is defined, and achieve the win-win between the governmental public capital and private capital.

\section{B. The VFM Assessment Should Maximize the Capital Utilization Efficiency}

If we think that the VFM assessment system and mechanism is used to distribute and protect the rights and benefits between governmental public capital and private capital so a sot exert the PPP's advantages as defined, how to maximize the utilization efficiency of the governmental public capital and private will be a higher goal for introducing the PPP mode. It is known that capital is to maximize the benefits of its own, that is, the lowest cost is expected to create the highest benefits with the shortest time. How can we achieve it? up to now, seen from the human wisdom and experience, marketization is the optimal method and way to optimize the resource allotment and capital. With the hand invisible, all resources and factors can be allotted and use with the highest efficiency for the max benefits. Therefore, the VFM assessment system shall also follow the market laws, and we need to consider how to exert the capital efficiency under the PPP mode so as to keep the capital mode powerful and energetic. Seen from a wider range, we should not only value the capita efficiency of the PPP mode, but also put the capital under the PPP mode into the whole capital formed together with other capital modes. If the mode's advantages and efficiency are risking the sacrifice of fair competition of other capital modes and damages of the whole capital environment order, the justification of the mode will be far to meet the requirements and expectation. Therefore, under the PPP mode, the governmental public capital just like the private capital, shall be kept careful before, during and after the investment and win the market share through the completely fair competition, and avoid the unfair result when competing with other capitals due to the interference of non-competitive factors.

\section{The VFM Assessment Shall Lower the Capital Risks to the Maximum}

It is now that what the capital focuses on are two points: first, capital security; second, maximum capital benefits. Classic economics told us, everyone is rational and calculating all what for the benefits of his own, that is everyone has the nature of self interest benefiting others based on it. (Refer to Hong Kong Ci Jiwei, the Two Faces of Justice: Chapter V Moral Limit of Rational Self Interest) It can also get proved by The Theory of Moral Sentiment and the Wealth of Nations written by Father of Economics, 
Adam Smith, it means that for the private capital, the owner will do all what he can to secure the capital. Yet for the public capital whose ownership is separated from management right, as a manager, whether the government will manage the public capital just like that of its own to guarantee the security of the public capital is not as good as you think. The PPP mode is an integration of private capital and public capital, which has unique risks of its own according to its nature. Therefore, the VFM assessment must depend on applicable systems and responsibility mechanism to reduce the capital risks and secure the capital to the maximum. For example, the VFM assessment group experts shall follow the avoidance system of the interested party, and even experts can be invited from other places for independent assessment so as to guarantee the impersonal and scientific assessment conclusion. In addition, relying on the work procedure and system arrangement, rights protection and responsibility and investigation for the VFM assessment experts, we can guarantee them to make full of professional knowledge, impersonal factors and power they hold to make relevant, impersonal and scientific assessment conclusion.

\section{The VFM Assessment Shall Be Operable}

The life of all laws and regulations relies in practice, which is also the goal of it. Therefore, the VFM assessment system shall be considered for operability, it needs to weigh the relations between general principles and specific provisions, quantitative and qualitative analysis. General principles are red line for the whole system arrangement, which lead and instruct the system. Once a system is established, the following articles must be consistent with it in spirit and principle, and it is a specific and operability design of the spirit and principle. Seen theoretically for specific provisions, the more detailed the articles, the easier the practice is. Yet we cannot know all cases in the real society. Therefore, we have remained spaces for the system design, which is just like a mesh but not a board. The mesh will make it applicable for experts to freely do what they can.

Seen from practice, during the implementation, it shall meet the articles of specific provisions, otherwise, the general principles shall make up for it. Therefore, it is not good for too more articles of general principles, and it will be ok as long as it may show the goal and orientation of the VFM assessment system. The specific provisions shall be detailed as possible as it can, and a clear operable way shall be made for before, during and after the procedures. During the whole course, any results that may arise has specific way to follow, and specific and procedural provisions shall be made to the experts' qualification, arrangement, rights guarantee and responsibilities as possible as we can.

As for the relations between qualitative analysis and quantitative analysis, the qualitative analysis is unclear and it is hard to weigh the specific results; the quantitative analysis may bring quantitative conclusion, and it is easy to specify the quantitative analysis, which is recommended as much as possible. What is noted especially is the quantitative indices of quantitative analysis has higher requirements, if the quantitative standard is over higher, it will block the PPP mode's healthy and sustainable development; if the quantitative standard is too lower, it will fail to work on the VFM assessment. Therefore, it is the key to quantify the indices, which need fully rational and scientific professional and special investigation before establishing the systems, get opinions and suggestions from all parties concerned, carefully design feasible quantitative indices what will do good to the PPP mode's healthy and sustainable development.

\section{E. The VFM Assessment Shall Have Clear Complaint Procedures}

It is said that remedy precedes rights. The important way to guarantee the rights and benefits of all parties for any system design is to give chances to all parties concerned to express. And the VFM assessment will get involved in owners of private capital, agents of public capital and others concerned. If one or more parties disagree on the assessment conclusion, channels and chances shall be given to them for complaint, which comply with the spirit and concept of modern legal society and go consists with the legal construction "law-based government, legal society and legal country", and also avoid serious flaws arising out of the VFM assessment, in addition, it may set the authority and prestige of the VFM assessment and systems and further promote the PPP mode's healthy and sustainable development. Therefore, the VFM assessment system design shall make operable rules concerning the complainant's qualification, complaint start and procedures.

\section{CONCLUSION}

The PPP-related VFM assessment becomes formalistic that is not the fault of the VFM concept, it is caused by the imperfect VFM assessment method. Seen from the jurisprudence, as an important system arrangement, the VFM should be improved from weighing the relations of rights and benefits of governmental public capital and private capital, maximizing the capital efficiency, minimizing the capital risk, operability and clear complaint procedures. In the meantime, we should set correct concepts for assessment, the VFM assessment shall not be used only for the PPP-based projects, it may avoid the phenomenon that even with the VFM assessment methods and statistic data perfected, the consultancy agents earn in the first round of PPP promotion and earn again through helping the parties concerned in the second round to deal with the worse situation, finally it will improve the efficiency and possibility of public-private cooperation.

\section{REFERENCES}

[1] Lai Danxin, Fei Fangyu, Public-Private Partnership Efficiency: Comprehensive Analysis, Economists, Jul 2010

[2] Ye Xiaoting, Xu Chunmei, Research and Review on Public-Private Partnership Mode in China, Soft Sciences, Jun 2013.

[3] Li Xia, Research and Review on Public-Private Partnership, Business Review, Aug 2014

[4] Zhao Ye, PPP Project Failure Cases Analysis and Risk Prevention in China, Sub National Fiscal Research, Jun 2015. 
[5] Deng Xiaopeng, Li Qiming, Xiong Wei, Yuan Jingfeng, Research on Key Risks for Urban Infrastructure PPP Projects, Modern Management Science, Dec 2009

[6] Zhou Xin, Analysis of Financing Risk Gambling for PPP Projects, Cooperative Economy \& Science, Period 14, 2009. 